\title{
The Impact of Smartphone Addictive Use by Students with Learning Disabilities on Social, Psychological and Academic Domains
}

\author{
Mayada Al-Natour ${ }^{1}$, Khaled Al-Ajlouni ${ }^{2}$, Hatem AlKhamra ${ }^{3},{ }^{1,3}$ School of \\ Educational Sciences, The University of Jordan, Jordan, ${ }^{2}$ College of Education, \\ Arab Open University - Jordan, Email: ${ }^{1}$ mnatour@ju.edu.jo, \\ ${ }^{2}$ k_ajlouni@aou.edu.jo, ${ }^{3}$ h.alkhamra@ju.edu.jo
}

The current study aimed at identifying the impact of the addictive use of smartphones by students with learning disabilities on the social, psychological and academic domains. The sample of the study consisted of 210 male and female students enrolled in classes of resource rooms of grades five to nine in public and private schools at the Ministry of Education in Amman governorate. The researcher developed two measures to achieve the goals of the study; the first is "a scale to measure the addiction of smartphones use", which contains 32 items, and another scale to measure the "impact of smartphones excessive use on social, emotional and academic domains", which contains (30) items. This process was preceded by a review of previous similar pedagogic studies. Validity and reliability significance were extracted. Results revealed that the estimation of the addictive use of smartphones by students of learning disabilities aged 11-15 was rated as average. Results also revealed that impact of smartphone use dominated the social and emotional aspects over the academic. Results call for the need to develop and practise some precocious interventions and early detection of the excessive use of smartphones in general, but above all by students with learning disabilities.

Key words: Addictive use of smartphones, Social, Emotional and academic domains, Learning disabilities 


\section{Introduction}

Communication means have developed through the revolutionary development of technology. Most of these inventions and instruments include supercomputers, telecommunication and peripheral devices with smartphones as the main tool for evolution; they are being used by all age groups and are playing a fundamental role in our lives.

It is noted that smartphones are becoming a vital part of our lives, making things easier through many applications including video and voice chat, the internet, and many uncountable applications (Daniela, Roberta, Ilaria, Marta, Eliabetta, Danilea, and Maria. 2019; Choudhary, 2014; Haug, Castro, Kwon, Filler, Kowtsch, and Schaum, 2015; Asli, Samet, Cemal, Serdar, Onat, and Nesrin, 2016). Globally it is estimated that around half of the world own a smartphone, the number of global smartphone users is projected to total 3.5 billion, with an average of 76 percent of adults in these countries report owning a smartphone. These percentages differ from one country to another and is usually higher in advanced economies in relation to developing countries. (Lee, Ahn, Choi \& Choi, 2014).

Despite the convenience offered by the use of technology, many health and specifically mental health issues are occurring due to the dramatic use of such technologies (Kim, Chung, Lee, Kim, Lee, Kang \& Nam, 2012). Behavioural addictions including smartphone addiction is rooted as part of the in the internet addiction through the similar symptoms and negative impacts on users.

Many terminologies have been used lately to describe internet addiction, some include psychological dependence as identified by Dowling \& Quirk (2009) as the attachment to a behaviour that cannot be stopped; it might cause withdrawal from life activities and feeling of emptiness when parted from the internet. Other have called it "Disorders of internet addiction" as a loss of control over impulses towards using the internet with no obvious goal and not combined with overdrinking, having drugs or loss of conscience (Saville, Gisbert, Kopp, \& Telesco, 2010).

An epidemiological study reported the negative effect of the excessive use of mobile phones, where it might lead to mental health problems (e.g. headaches, fatigue, impaired concentration, insomnia, and hearing problems). Furthermore, it revealed that the following dimensions like low self-esteem, extraversion, higher approval motivation, and higher self-monitoring are usually seen in this group (Danilo, Nami, and Jinsoo, 2019; Asli, Samet, Cemal, Serdar, Onat, and Nesrin, 2016). In addition, sleeping problems is another aspect that is highly affected by the use of mobile phones; the late or irregular sleeping patterns due to mobile rings and vibrations disrupts the sleeping cycle which might lead to depression, social anxiety and other instabilities (Kalsoom, Rukiya, Ayesha, Abdullah, and Maryam, 2019; Daniela et al., 2019). 
Recent research depicting the use of mobile phones indicated that about $40 \%$ of adolescents and adults use smartphones more the 4 hours a day making calls and sending messages. This sample showed more problems in social and emotional health compared to others who use smart phones for less than 4 hours a day (Pearson \& Hussain, 2015; EnezDarcin, Kose, Noyan, Nurmedov, Yilmaz, and Dilbaz, 2016; Aljomaa, AlQudah, Albursan, Bakhiet, and Abduljabbar, 2016; Sarti, Bettoni, Offredi, Tironi, Lombardi, Traficante, and Luisa Lorusso. 2019).

Another study was concerned with finding out the time college students spend on using social media, and why do they use it? The sample consisted of 92 students at Georgetown University in the USA, where researchers used a survey method to gather data. Results showed that college students use Facebook for approximately 30 minutes a day as part of their daily routine (Tiffany, Yevdokia, and Sandra, 2009).

Several studies found a negative relation between the multi-tasking of smartphones and a low academic performance in a sample that consisted of 451 students at different USA universities; the study revealed that students use of Facebook and texting while studying, doing assignments or attending classes have negative effects on their academic level (Karpinski, Kirshner, Ozer, Mellot, and Ochwo, 2013).

Furthermore, smartphone addiction doesn't correlate positively with satisfaction in life, rather with fatigue and low academic performance (Junco \& Cotton 2012; Samaha, and Hawi, 2016). This addiction causes loss of concentration for many students due to night calls, which lead to their drowsiness at class time (Walsh, White, \& Young, 2009), and probably they will have less time for studying (Aljomaa et al, 2016).

A study conducted by Tossell, Kortum, Shepard, Rahmati, Linzhong, (2015) resulted in that misuse of smartphones lead to the spread of psychological issues like depression, isolation and introversion, refusing community values and a shift in religious beliefs to be replaced by values of other users especially among adolescents and college students. The effect of using yhe smartphone of the both genders, Park \& Lee (2012) found out that males and females use smartphones in different manners, where females tend to use the camera applications, while males prefer calls to widen their connections. Nevertheless, smart phones provide shy people an ideal environment that makes them less lonely, and they might even share various activities, like internet games, taking photographs and making videos, searching for news, texting friends and reading online books. People with a high level of social anxiety would prefer virtual communication than the real life communication (Weinstein, Dorani, Elhadif, Bukovza, Yarmulnik, \& Dannon, 2015).

Bian and Leung (2015) confirmed that excessive use of smartphones reduces social signals like "non-verbal signals" such as facial expressions and gestures, because it affects the ability to detect and understand social signals, which leads to more isolation and higher dependence 
on smartphones. Both researchers confirmed that communication through texting is considered safer than direct contact considering the unexpected judgment of others (Yen, Yen, Chen, Wang, Chang and Ko, 2012).

Furthermore, the use of smartphones might isolate people from their social surroundings by concentrating on a single act for a long period of time; then this repetitive action becomes so joyful that a person cannot stop, and when they try to, it will have a negative impact of stress and anxiety (Park, Kee, and Valenzuela, 2009; Leung and, Lee, 2011).

One of the Arabic studies concerned with impacts of smartphone addiction (Abo Jedi, 2018) aimed at identifying the level of addiction on smartphones by a sample of college students at Jordan University and Al- Ahliyya Amman University, where a scale was developed to measure the level of addiction on a sample of 480 male and female students from both universities. Results showed that $25.8 \%$ of students were addicted, with females having higher levels of addiction compared to male students; it was noticed that addiction is higher in private universities compared to public universities.

Another study was conducted by (Ben-Yahuda, Greenberg and Weinstein, 2016) to investigate the relation between using smartphones and internet addiction and the level of norms of using the internet (boredom, negative activity, active activity) among males and females; the sample consisted of 40 male and female college students aged 21-29. Results revealed a correlation between repetitive use of smartphones and internet addiction, also an increase in the average of internet usage than the activity being used.

According to the high emphasis on the addictive state of smartphone usage, the researchers wanted to reveal the impact smartphones have on students with learning disabilities. Students with learning disabilities have their own characteristics which can be easily affected by the misuse and abuse of smartphones. The idea and the desire was to use smartphones as a safe haven away from face-to-face interactions, avoiding frustration in the academic learning community, and the many stories of success of others and the need to adapt and belong to their surroundings. In addition, those students feel less capable to progress and develop in learning despite the effort they make to follow their peers (Heward, 2012, Panicker \& Chelliah, 2016).

The value of the study appears in discussing the misuse of smartphones that might become an "addiction", and the relation of this addiction of modern technology gadgets with social, psychological and academic problems. In addition to the targeted sample that represents an important age stage of (11-15) that needs to be developed and to be taken care of socially psychologically and academically. This study will provide professionals and decision-makers with a reference to consider the danger of smartphone addiction. 


\subsection{Statement of the problem and questions of the study}

Smartphones caused a revolutionary change in our lives, basically on the social, psychological and academic domains among students in general, but mainly on students with learning disabilities, which led to a different norm of life style, and an enormous knowledge explosion of data and info that you get so quickly. But this progress had its impact on a change that was not in all positive, which led to certain problems with students that have learning disabilities. Many international and national studies covered the subject of students with learning disabilities, but few of them investigated addiction of smartphones. We all notice the excessive and time consuming use of smartphones by children; among them are those with learning disabilities, to the extent that they become addictive. Thus, our study is concerned with identifying the average of smartphone addiction among students with learning disabilities, and trying to figure out the most affected domain of their social, psychological or academic life. The paper seeks to answer the following questions:

1. What is the average addictive use of smartphone by students with learning disabilities aged $11-15$ ?

2. Which domain (social, psychological, academic) is mostly affected by the addictive use of smartphones by students with learning disabilities aged (11-15)?

\subsubsection{Aims of the study}

The study aimed at identifying the average of smartphone addiction by students with learning disabilities and which domain is mostly affected by this addiction (social, psychological or academic)?

\subsubsection{Significance of the study}

The study considers a current issue which will provide a theoretical frame to benefit educators, parents, and researchers to observe the negative impacts of smartphone addictive use on the behaviour of students with learning disabilities. Results of the study will help to develop procedures and methods to follow for a wise use of smartphones, and encourage students towards the right direction through precautious procedures and setting some treatment plans.

\subsubsection{Terms of the study}

- Smartphone addiction

A state of compulsive overuse of smartphones which can't be controlled (Pearson \& Hussain, 2015). It was identified by (Alkhamayseh, 2017) as a common phenomenon 
International Journal of Innovation, Creativity and Change. www.ijicc.net

Volume 15, Issue 2, 2021

among individuals that have excessive use of smartphones which can affect their personal and professional life and they might even neglect friends and families.

\section{Method and procedure}

Includes a description of the procedures followed, in addition to a description of the sample and the tools used for the purpose of the study, and the statistical process that will be used to analyse data and extract results.

\subsection{Sample of study}

A sample of the study consisted of 210 male and female students with learning disabilities aged 11-15 in Amman. The sample was selected according to availability, where they worked with the researchers at some private and public schools in Amman during the first school semester of 2019/2020, distributed according to gender as obvious in tables $(1,2)$ below:

Table (1): distribution of individuals according to gender and grade

\begin{tabular}{lll}
\hline Gender & Number & Percentage \\
\hline Male & 122 & $58 \%$ \\
Females & 88 & $41 \%$ \\
Total & 210 & $100 \%$ \\
\hline
\end{tabular}

Table (2) distribution of individuals according to variable of

\begin{tabular}{lll}
\hline Grade & Number & Percentage \\
\hline Fifth & 13 & $6.2 \%$ \\
Sixth & 20 & $9.5 \%$ \\
Seventh & 62 & $29.5 \%$ \\
Eighth & 65 & $31.0 \%$ \\
Ninth & 50 & $23.8 \%$ \\
Total & 210 & $100 \%$ \\
\hline
\end{tabular}

\subsection{Method of the study}

A descriptive, analytical method was used to reach the purpose of the study, by identifying the average of smartphone addiction by the sample students. This method was considered reliable for the study. 


\subsection{Instrument of the study}

To achieve purpose of the study by identifying the average of smartphone addiction by students with learning disabilities, the researcher developed a scale to measure smartphone addiction and the addiction effect on social, psychological and academic domains. Items of the tools were formed referring to theoretical pedagogy in education technology and special needs education, in addition to the over-viewing of some other scales of smartphone addiction,; the following is an overview of the procedures of establishing the scales:

\subsubsection{First: a scale to measure smartphone addiction}

This scale is developed to measure the level of smartphone addiction by students with learning disabilities, which consists of 32 items. The researcher followed the below procedures to establish the scale:

- Review of previous pedagogic studies.

- A procedural identification of smartphones addiction use by students with learning disabilities to comply with the current study.

- Items of the study were formulated as phrases to be answered on a scale of strongly agree (4), agree (3), disagree (2), strongly disagree (1) (where the scale from 1-2 is considered low, between (2-3) is averaged, and is high (3-4)).

- The first draft of the scale consisted of33 items.

\subsubsection{Validity of the Instrument}

The first draft of the instrument was reviewed by 13 arbiters with a variety of specialised domains like special education, psychological counselling, education technology, evaluation and assessment from several Jordanian universities to study the appropriate items of the local Jordanian community; they call for some changes and deletion and addition of items which appeared as the final copy of the instrument of 32 items.

\subsubsection{Reliability of the instrument}

To confirm reliability of the scale of smartphone addiction instrument, reliability coefficients were measured in two ways: first was testing and retesting, which was conducted on an identical pilot sample outside the sample of the current study. There were 30 students and it was conducted two times in a two week period. The reliability coefficient of the scale was 0.48 . Second is using the Cronbach alpha coefficient to observe internal coherence of the items, where the reliability coefficient of the instrument was 0.89 and 0.95 , which represented an acceptable figure to conduct the study. 
International Journal of Innovation, Creativity and Change. www.ijicc.net

Volume 15, Issue 2, 2021

\subsubsection{Second: a scale to measure the impact of smartphone addiction on the "social, psychological "and "academic" domains}

This instrument was considered to measure the impact of smartphone addiction on the social, psychological and academic domains of students with learning disabilities. It consisted of 30 items distributed into two categories: the social /psychological aspect, 16 items, and the academic aspect with 14 items. The researcher followed the below procedure to construct the instrument:

- Review of the related literature, by referring to studies of Aljomaa, et al. 2016; Pearson, \& Hussain, 2015; EnezDarcin, et al., 2016.

- Procedural identification of the use of smartphones by students with learning disabilities to comply with the purpose of the current study.

Items of the study were formulated as phrases to be answered on a scale of strongly agree (4), agree (3), disagree (2), strongly disagree (1) (where the scale from 1-2 is considered low, between (2-3) is averaged, and is high (3-4)).

\subsubsection{Validity of the instrument}

The first draft of the instrument was reviewed by 13 arbiters with a variety of specialised domains like special education, psychological counselling, education technology, and evaluation and assessment from several Jordanian universities to study the appropriate items of the local Jordanian community; they call for some changes and deletion and addition of items which appeared as the final copy of the instrument of 30 items.

\subsubsection{Reliability of the instrument}

To confirm reliability of the scale of smartphone addiction instrument, reliability coefficients were measured in two ways: first was testing and retesting, which was conducted on an identical pilot sample outside the sample of the current study. There were 30 students and it was conducted two times in a two week period. The reliability coefficient varied between 0.760.81, where the total coefficient value was 0.91. Second, was the use of the Cronbach alpha coefficient to observe the internal coherence of the items where the coefficient varied between 0.79- 0.85 and 0.95 for the total instrument. These are acceptable to conduct the study; Table 3 shows the reliability coefficients amounts for the domains of the scale in the Cronbach alpha method. 
International Journal of Innovation, Creativity and Change. www.ijicc.net

Volume 15, Issue 2, 2021

Table 3. Amount of reliability coefficients for repletion and internal coherence for each domain in the scale

\begin{tabular}{lccc}
\hline No. & Domain & \multicolumn{2}{c}{ Reliability coefficient values } \\
& & Repetition & Cronbach alpha \\
\hline 1 & Academic & 0.81 & 0.85 \\
2 & Social, psychological & 0.78 & 0.81 \\
\multicolumn{2}{l}{ Total instrument } & 0.91 & 0.95 \\
\hline
\end{tabular}

\section{Findings and Discussion}

This part is concerned with a display of the results after data being collected and analysed according to the questions of the paper.

\subsection{Results of the first question}

What is the average of smartphones addictive use by students with learning disabilities at the age of 11-15?

To answer this question, ratios and standard deviations were calculated for the estimations of the ratios of addictive use of smartphones by students with learning disabilities at the age of 11-15, as shown in Table 4.

Table 4. Ratios and standard deviations for the estimations of the sample on the items of addictive use of smartphones by students with learning disabilities at the age of 11-15 arranged descending according to ratios.

Table 4: The ratios of addictive use of smartphones by students with learning disabilities

\begin{tabular}{|c|c|c|c|c|c|}
\hline rank & $\begin{array}{l}\text { No. } \\
\text { of } \\
\text { item }\end{array}$ & items & Ratio* & $\begin{array}{l}\text { Standard } \\
\text { deviation }\end{array}$ & level \\
\hline 1 & 32 & My phone was often confiscated at school & 2.80 & 1.14 & Medium \\
\hline 2 & 19 & $\begin{array}{l}\text { I lost a lot of weight since I started using } \\
\text { smartphones }\end{array}$ & 2.69 & 1.10 & Medium \\
\hline 3 & 20 & $\begin{array}{l}\text { I gained a lot of weight since I started using } \\
\text { smartphones }\end{array}$ & 2.52 & 1.09 & Medium \\
\hline 4 & 30 & I sleep with the phone in my hand & 2.48 & 1.05 & Medium \\
\hline 5 & 5 & $\begin{array}{l}\text { I prefer sitting to play with my phone than } \\
\text { visiting relatives }\end{array}$ & 2.40 & 1.76 & Medium \\
\hline 6 & 11 & I have little sleep due to use of the phone & 2.36 & 1.09 & Medium \\
\hline
\end{tabular}


International Journal of Innovation, Creativity and Change. www.ijicc.net

Volume 15, Issue 2, 2021

\begin{tabular}{|c|c|c|c|c|c|}
\hline 7 & 4 & I prefer playing on my phone than with friends & 2.33 & 1.09 & Medium \\
\hline 8 & 14 & I open my phone right after I wake up & 2.27 & 1.09 & Medium \\
\hline 9 & 8 & I am annoyed when my phone breaks down & 2.26 & 0.99 & Medium \\
\hline 10 & 29 & $\begin{array}{l}\text { I don't tell my parents the truth about the time I } \\
\text { spend on my phone }\end{array}$ & 2.26 & 1.03 & Medium \\
\hline 11 & 31 & It annoys me that the battery lasts only one day & 2.25 & 1.06 & Medium \\
\hline 12 & 7 & $\begin{array}{l}\text { Using the phone constantly causes pain in my } \\
\text { hand, neck and back }\end{array}$ & 2.23 & 1.04 & Medium \\
\hline 13 & 26 & I fail whenever I try to decrease using my phone & 2.23 & 1.07 & Medium \\
\hline 14 & 9 & I get busy with my phone and neglect our guests & 2.22 & 1.03 & Medium \\
\hline 15 & 24 & $\begin{array}{l}\text { If I don't use my phone, I tend to quarrel with } \\
\text { my family }\end{array}$ & 2.21 & 1.04 & Medium \\
\hline 16 & 3 & I eat food with the phone in my hand & 2.19 & 1.12 & Medium \\
\hline 17 & 16 & I keep using my phone even when I am sleepy & 2.18 & 1.03 & Medium \\
\hline 18 & 28 & $\begin{array}{l}\text { I always keep the charger with me, in case the } \\
\text { battery gets low }\end{array}$ & 2.18 & 1.03 & Medium \\
\hline 19 & 15 & I am addicted to smartphones & 2.15 & 1.11 & Medium \\
\hline 20 & 25 & I get angry when I forget my phone somewhere & 2.15 & 1.03 & Medium \\
\hline 21 & 13 & I keep on using my phone even when I am tired & 2.14 & 1.06 & Medium \\
\hline 22 & 18 & My parents scold me for overuse of my phone & 2.13 & 1.01 & Medium \\
\hline 23 & 6 & $\begin{array}{l}\text { I'm stressed when being deprived from using } \\
\text { my phone }\end{array}$ & 2.12 & 1.00 & Medium \\
\hline 24 & 12 & $\begin{array}{l}\text { My parents often warn me for my excessive use } \\
\text { of my phone }\end{array}$ & 2.11 & 1.07 & Medium \\
\hline 25 & 10 & Wherever I go, I got busy with my phone & 2.10 & 0.97 & Medium \\
\hline 26 & 27 & I keep checking my phone & 2.07 & 1.06 & Medium \\
\hline 27 & 21 & $\begin{array}{l}\text { I keep thinking of my phone when I practise } \\
\text { other activities }\end{array}$ & 2.06 & 0.98 & Medium \\
\hline 28 & 17 & Time flies when I use my phone & 2.00 & 1.01 & Medium \\
\hline 29 & 23 & $\begin{array}{l}\text { I spend more than the allowed time on my } \\
\text { phone }\end{array}$ & 1.96 & 1.04 & Low \\
\hline 30 & 2 & $\begin{array}{l}\text { I'm annoyed when somebody talks to me while } \\
\text { using my phone }\end{array}$ & 1.94 & 0.93 & Low \\
\hline 31 & 1 & I get bored when not using my phone & 1.88 & 0.97 & Low \\
\hline 32 & 22 & I use my phone to feel better & 1.83 & 0.98 & Low \\
\hline \multicolumn{2}{|c|}{ Total } & & 2.21 & 0.53 & Medium \\
\hline
\end{tabular}

* highest rate is 4

Table 4. above shows that averages of items of the measure scale is 1.83-2.80, and that item 32 which says "My phone was often confiscated at school" was ranked first with a ratio of 2.80 and a standard deviation of 1.14 and was levelled as medium. While came in the second place 
the phrase that says "I lost a lot of weight since I started using a smartphone", with a ratio of 2.69 and a standard deviation of 1.10 and levelled also as medium. As for item 22 which says "I use my phone to feel better", it was ranked last with a ratio of 1.83 and a standard deviation of 0.98 and levelled as low. The total ratio of estimation of participants of the sample on the item of the instrument for students with learning disabilities at the age $11-15$ was 2.21 and a total standard deviation of 0.53 and levelled as medium which suggest that there is an addiction on smartphones in the category assigned.

Results reveal the fact that thereis an addiction on smartphone usage by students with learning disabilities at the age of 11-15. The researchers might refer the reason to that they are adolescents, which is a main factor of their interest in smartphones and the internet, which they can easily have an access to wherever they are, which is becoming more easy with low cost. Results also agree with previous studies like those of Aljomaa et al, 2016, Griffiths, 2013, but studies are not to be compared due to the differences of the sample, where the current study was concerned with students with learning disabilities. The researchers also refer the result to the fact that students with learning disabilities tend to be more bored, and smartphones provide them with variant activities, prompt responses, and direct rewarding, which differs from the actual environment. Low achievement and low motivation, frustration for not being able to follow up with their peers might push them towards excessive use of smartphones.

\subsection{Results of the second question}

Which domain (social, psychological, academic) is mostly affected by the addictive use of smartphones by students with learning disabilities aged 11-15?

To be able to answer the question, a calculation of ratio and standard deviation was made on the estimation of the sample of students with learning disabilities at age 11-15 on the most affected aspect, as displayed in table (5) below:

Table 5. Ratio and standard deviation were made on the estimation of the sample of students with learning disabilities at age 11-15 on the most affected domain, ranked descending according the ratios

\begin{tabular}{lllcc}
\hline Rank & No. & Domain & Ratio* & Standard deviation \\
\hline 1 & 1 & Social and psychological & 2.21 & 0.64 \\
2 & 2 & Academic & 2.13 & 0.60 \\
\multicolumn{2}{l}{ Total instrument } & 2.17 & 0.59 \\
\hline
\end{tabular}

* Highest ratio is 4 
Table 5. displays that the social psychological domain was ranked first with a ratio of 2.21 , a standard deviation of 0.64 and as a total for the whole sample the ratio was 2.17 and the standard deviation was 0.59 .

Also ratios and standard deviations were calculated for the estimations of the sample on the most affected domain (social, psychological and academic) on students with learning disabilities at the age of $11-15$, as follows:

\subsubsection{First domain: the social, psychological domain}

Ratios and standard deviation for the estimations of the sample of students with learning disabilities at the age of 11-15 on the most affected domains (social, psychological or academic) as displayed in table (6).

Table 6. Ratios and standard deviation for the estimations of the sample on items of social and psychological ranked descending according to ratio

\begin{tabular}{|c|c|c|c|c|}
\hline Rank & $\begin{array}{l}\text { No. } \\
\text { of } \\
\text { Item }\end{array}$ & Items & Ratio* & $\begin{array}{l}\text { Standard } \\
\text { deviation }\end{array}$ \\
\hline 1 & 18 & I prefer internet friendships than school friends & 2.48 & 1.06 \\
\hline 2 & 17 & $\begin{array}{l}\text { Being occupied with my phone decreases my attending } \\
\text { clubs or school committees }\end{array}$ & 2.35 & 1.05 \\
\hline 3 & 25 & $\begin{array}{l}\text { Using a smartphone pushes me away from connecting } \\
\text { with people around me }\end{array}$ & 2.30 & 1.06 \\
\hline 4 & 22 & $\begin{array}{l}\text { Being occupied with my phone keeps me away from } \\
\text { friends }\end{array}$ & 2.25 & 1.10 \\
\hline 5 & 19 & I have more friends on the internet than real friends & 2.24 & 1.13 \\
\hline 6 & 26 & $\begin{array}{l}\text { I can express myself with no critic or comments using a } \\
\text { smartphone }\end{array}$ & 2.18 & 1.08 \\
\hline 7 & 20 & $\begin{array}{l}\text { Being occupied with my phones make me less talkative } \\
\text { with my family }\end{array}$ & 2.16 & 1.05 \\
\hline 8 & 23 & $\begin{array}{l}\text { I find it easier to write in the slang language on my } \\
\text { smartphone }\end{array}$ & 2.10 & 1.01 \\
\hline 9 & 27 & I feel I can be a decision-maker using my phone & 2.08 & 1.09 \\
\hline 10 & 16 & $\begin{array}{l}\text { I had better relations with others since I started using a } \\
\text { smartphone }\end{array}$ & 2.06 & 1.04 \\
\hline 11 & 30 & $\begin{array}{l}\text { I like the language of the smartphone because it doesn't } \\
\text { follow the rules of the standard language }\end{array}$ & 2.03 & 1.07 \\
\hline
\end{tabular}


International Journal of Innovation, Creativity and Change. www.ijicc.net

Volume 15, Issue 2, 2021

\begin{tabular}{|c|c|c|}
\hline 29 & I prefer application games more than physical activities & 2.01 \\
\hline 24 & $\begin{array}{l}\text { I don't think my distraction has a connection to use of a } \\
\text { smartphone }\end{array}$ & 1.97 \\
\hline 15 & $\begin{array}{l}\text { I use my phone to contact with class peers about } \\
\text { assignments I forgot about }\end{array}$ & 1.97 \\
\hline 21 & Excessive use of my phone made me lose friends & 1.94 \\
\hline 28 & $\begin{array}{l}\text { A smartphone helps me to remember things through the } \\
\text { alarm }\end{array}$ & 1.2 \\
\hline
\end{tabular}

Total domain

$2.13 \quad 0.60$

*highest ratio is 4

Table (6) displays that item 18 which reads "I prefer internet friendships than school friends" was ranked as first with a ratio of 2.48 and a standard deviation of 1.06 which is considered high, while item 17 which reads "Being occupied with my phone decreases attending clubs or school committees" which ranked second with a ratio of 2.35 and a standard deviation of 1.05 which is considered high; as for the item 28 which was ranked last, reads "A smartphone helps me to remember things through the alarm" with a ratio of 1.92 and a standard deviation of 0.98 which is considered medium. As for the ratio of the total domain, it reached 2.13 with a standard deviation 0.60 which is considered high.

\subsubsection{Second domain: Academic}

Ratios and standard deviation for the estimations of the sample of students with learning disabilities at the age of 11-15 on the most affected domains (social psychological or academic) as displayed in table (7). 
Table 7. Ratios and standard deviation for the estimations of the sample on items of the academic domain

\begin{tabular}{|c|c|c|c|c|}
\hline rank & $\begin{array}{l}\text { No. } \\
\text { of } \\
\text { Item }\end{array}$ & items & Ratio* & $\begin{array}{l}\text { Standard } \\
\text { deviation }\end{array}$ \\
\hline 1 & 3 & $\begin{array}{l}\text { I'm late at handing in my assignments because I'm always } \\
\text { busy on my phone }\end{array}$ & 2.61 & 1.05 \\
\hline 2 & 5 & I rely on my phone for spelling correction & 2.48 & 1.06 \\
\hline 3 & 9 & $\begin{array}{l}\text { I try to finish my assignment quickly to go back to my } \\
\text { phone }\end{array}$ & 2.40 & 1.14 \\
\hline 4 & 14 & $\begin{array}{l}\text { I prefer writing in abbreviations when texting more than } \\
\text { hand writing }\end{array}$ & 2.40 & 1.06 \\
\hline 5 & 7 & $\begin{array}{l}\text { Smartphone applications like the dictionary helps me with } \\
\text { my school work }\end{array}$ & 2.38 & 1.07 \\
\hline 6 & 13 & $\begin{array}{l}\text { I prefer writing in abbreviations when texting more than } \\
\text { hand writing }\end{array}$ & 2.28 & 1.11 \\
\hline 7 & 6 & I use application of auto talk to read some difficult words & 2.15 & 1.04 \\
\hline 8 & 8 & $\begin{array}{l}\text { Being occupied with my phone makes me neglect my } \\
\text { homework }\end{array}$ & 2.10 & 1.08 \\
\hline 9 & 2 & Using my phone reduces my time of study & 2.08 & 1.04 \\
\hline 10 & 4 & $\begin{array}{l}\text { I use the application of the calculator instead of thinking } \\
\text { of numbers }\end{array}$ & 2.08 & 1.04 \\
\hline 11 & 11 & I use the easier texting language in Arabic and English & 2.06 & 1.14 \\
\hline 12 & 1 & I prefer smartphone games more than doing my homework & 2.04 & 1.07 \\
\hline 13 & 12 & $\begin{array}{l}\text { I prefer using symbols and photos instead of writing on } \\
\text { my smartphone }\end{array}$ & 1.96 & 1.05 \\
\hline 14 & 10 & $\begin{array}{l}\text { I don't think there's a relation between my use of } \\
\text { smartphone and my low academic performance }\end{array}$ & 1.90 & 1.03 \\
\hline \multicolumn{3}{|c|}{ Total domain } & 2.21 & 0.64 \\
\hline
\end{tabular}

*highest ratio is 4

Table (7) displays that item 3 that reads 'I'm late at handing out my assignments because I'm always busy on my phone" was ranked first with a ratio of 2.61 and a standard deviation of 1.05 with high level, and the item "I rely on my phone for spelling correction" was ranked second with a ratio of 2.48 and a standard deviation of 1.06 with a high level of estimation. 
Item 10 "I don't think there's a relation between my use of smartphone and my low academic performance" was ranked last with a ratio of 1.90 and a standard deviation of 1.03 with a medium level; as for the total of the domain , the ratio was 2.21 with a standard deviation of 0.64 which is measured as high.

\section{Discussion}

Results revealed that the "social, psychological" domain was affected by excessive use of smartphones more than the academic domain, which the researchers think it is due to the desire of the students with learning disabilities to dwell in the virtual world they interact with rather than the real world that doesn't adapt to their needs; it also decreases their social attachments and stop them from being exposed to social and psychological encounters that reveal their weaknesses. In addition to the fact that students with learning disabilities feel more socially adaptable while communicating with others on their smartphones, because they lack the ability to make some real positive social communication, also, it makes them capable of facing stress and sharing things with others and better adaptation. This is usually reflected in some social problems they have to deal with, which correspond with results of other studies like those of Bian, \& Leung, 2016; Yen, Yen, Chen, Wang, Chang and Ko, 2012; Panicker, \& Chelliah, 2016.

\section{Recommendations}

The current study presented experimental guides that make us more aware of smartphone addiction. We became aware that students with learning disabilities who face the risk of being addicted to smartphones tend to show high levels of social and psychological problems, and the ill norm of their communicating with others.

Norms of using a smartphone might vary according to the personal circumstances of the user and their habits of usage; more studies should consider the subject.

Recommendations are made for more future studies that include other age categories taking into consideration the widespread use of technology; yet, studies on the domain are limited especially concerning people with learning disabilities, and efforts should be made try to eliminate negative impacts of technology and make use of its positive ones.

Funding: This study received no specific financial support.

Competing Interests: The authors declare that they have no competing interests.

Acknowledgement: All authors contributed equally to the conception and design of the study. 


\section{References:}

Abu Jadi. A. (2018). The impacts of smartphone addiction on self-disclosure of a college students at Jordan University and AlAhliyya Amman University. Jordan journal of educational sciences, Al- Yarmouk university, 4(2), 137-150

Alasdair A., and Philips J. (2017). Digital Enhanced Cordless Telecommunication or DECT phones. [Online] Available at: http://www.powerwatch.org.uk

Aljomaa, S., AlQudah., M., Albursan, S., Bakhiet, F., and Abduljabbar, S. (2016). 'Smartphone addiction among university students in the light of some variables'. Computers in Human Behavior, 61, 155-164.

American Psychiatric Association. (2013). Diagnostic and Statistical Manual of Mental Disorders, 5th Edition: DSM-5. Washington (DC): American Psychiatric Association.

Asli, E., Samet, K., Cemal, O., Serdar, N., Onat, Y., and Nesrin, D. (2016). Smartphone addiction and its relationship with social anxiety and loneliness. Behavior \& Information Technology, 35(7), 520-525

Ben-Yehuda, L., Greenberg, L., and Weinstein, A. (2016). Internet Addiction by using the smartphone-relationships between internet addiction, frequency of smartphone use and the state of mind of male and female students. Journal of Reward Deficiency Syndromes and Addiction Science, 2(1), 22-27.

Bian, L., and Leung, L. (2015). Linking loneliness, shyness, smartphone addiction symptoms, and patterns of smartphone use to social capital. Social Science Computer Review, 33(1), 61-79.

Cha Seong-Soo, and Seo Bo-Kyung. (2018). Smartphone use and smartphone addiction in middle school students in Korea: Prevalence, social networking service, and game use Health psychology open.

Choudhary, A. (2014). Smart phones and their impact on net income per employee for selected U.S. firms. Review of Business and Finance Studies, 5(2), 9-17.

Daniela, S., Roberta, B., Ilaria, O., Marta, T., Eliabetta, L., Danilea, T., and Maria, L. (2019). Tell Me a Story: Socio-Emotional Functioning, Well-Being and Problematic Smartphone Use in Adolescents with Specific Learning Disabilities. Frontiers in Psychology, 6, 1-8.

Danilo, B., Nami, K., and Jinsoo, J. (2019). Factors associated with smartphone addiction prevalence and its predictive capacity for health-related quality of life among Filipino adolescents. Children and Youth Services Review, 110, 1-12.

Divan H., Khelfets L., and Obel C. (2012) Cell phone use and behavioral problems in young children. Journal of Epidemiology \& Community Health, 66, 524-539.

Dowling, A. \& Quirk, L. (2009). Screening for internet dependence: Do the proposed diagnostic criteria differential normal from dependent internet use? Cyber psychology \& Behavior, 12 (1), $21-27$.

EnezDarcin, A.,Kose, S., Noyan, C., Nurmedov, S., yilmaz, O., \& Dilbaz, N. (2016). Smartphone addiction in relation with social Anxiety and loneliness among university student in turkey. Behavior \& Information Technology, 35(7), 520-525. 
Griffiths, D. (2013). Adolescent mobile phone addiction: A cause for concern? Education and Health, 31, 76-78.

Haug, S., Castro, R., Kwon, M., Filler, A., Kowtsch, T., and Schaum, M. (2015). Smartphone use and smartphone addication among young people in Switzerland. Journal of Behavioral Addictions, 4(4) 299-307.

Heron, D., and Shapira, NA. (2004). Time to log off: New diagnostic criteria for problematic internet use. Current Psychiatry 2(4), 21-29.

Heward, W. (2012). Exceptional children: An introduction to Special Education (10th Ed.). Upper Saddle River, NJ: Pearson Educational.

Junco, R., S.R. Cotton. (2012). No a 4 U: the relationship between multitasking and academic performance. Computers \& Education, 59(2), 505-514.

Kalsoom, T., Rukiya, T., Ayesha, Abdullah, H., and Maryam, S. (2019). Effects of smartphone usage on psychological wellbeing of school going children in Lahore, Pakistan. The Journal of the Pakistan Medical Association, 69(7), 955-958.

Karpinski, C., Kirschner, A., Ozer, I., Mellott, A., Ochwo, P. (2013). An exploration of social networking site use, multitasking, and academic performance among United States and European university students. Computers in Human Behavior, 29(3), 1182-1192.

Kim, D. I., Chung, Y. J., Lee, J. Y., Kim, M. C., Lee, Y. H., Kang, E. B., ... \& Nam, J. (2012). Development of smartphone addiction proneness scale for adults: Self-report. The Korean Journal of Counseling, 29, 629-644.

Lee, H., Ahn, H., Choi, S., \& Choi, W. (2014). The SAMS: Smartphone addiction management system and verification. Journal of medical systems, 38(1), 1.

Leung, L., \& Lee, N. (2011). The influence of information literacy, internet addiction and parenting styles on internet risks. New Media and Society.

Li, W., O'Brien, E., Snyder, M., \& Howard, O. (2015). Characteristics of internet Addiction pathological internet use in U.S. university students: A qualitative - method investigation.

Panicker, A. S., \& Chelliah, A. (2016). Resilience and Stress in Children and Adolescents with Specific Learning Disability. Journal of the Canadian Academy of Child and Adolescent Psychiatry, 25 (1), 17-23.

Park, N. \& Lee, H. (2012). Social implications of smartphone use: Korean college students' smartphone use and psychological well-being. Cyberpsychol Behave SocNetw.

Park, N., Kee, F., and Valenzuela, S. (2009). Being immersed in social networking environment: Facebook groups, uses and gratifications, and social outcomes. Cyber psychology and Behavior, 12, 729-733.

Pearson, C., \& Hussain, Z. (2015). Smartphone use, addiction, narcissism, and personality: A mixed methods investigation. International Journal of Cyber Behavior, Psychology and Learning, 5(1), 17-32.

Samaha, M., and Hawi, N. (2016). Relationships among smartphone addiction stress, academic performance, and satisfaction with life. Computers in Human Behavior 57 321-325. 
International Journal of Innovation, Creativity and Change. www.ijicc.net

Volume 15, Issue 2, 2021

Sarti, D., Bettoni, R., Offredi, I., Tironi, M., Lombardi, E., Traficante, D., Luisa Lorusso, M. (2019). Tell Me a Story: Socio-Emotional Functioning, Well-Being and Problematic Smartphone Use in Adolescents With Specific Learning Disabilities, Frontiers in Psychology, 10, 1-8.

Saville, K., Gisbert, A., Kopp, J. \& Telesco, K. (2010). Internet Addiction and Delay Discounting in college students. Psychological Record, 60(2), 273-288.

Tiffany P., Yevdokiya, Y., and Sandra, C. (2009). College students' social networking experiences on Facebook. Journal of Applied Developmental Psychology 30(3) 227-238.

Tossell, C., Kortum, P., Shepard, C. Rahmati, A. \& Linzhong, I. (2015). Exploring smartphone Addiction: insights from long - term telemetric Behavioral measures. International Journal of Interactive Mobile Technologies, 9(2), 37 - 43.

Walsh, S., White, K., \& Young, R.. (2009). The phone connection: a qualitative exploration of how belongingness and social identification relate to mobile phone use amongst Australian youth. Journal of Community \& Applied Social Psychology, 19(3), 225-240.

Weinstein, A., Dorani, D., Elhadif, R., Bukovza, Y., Yarmulnik, A., \& Dannon, P. (2015). Internet addiction is associated with social anxiety in young adults. Annals of Clinical Psychiatry, 27(2), 2-7.

Wong Bernice. (2004). Learning about Learning Disabilities, (third edition). Academic Press.

Yen, J-Y., Yen, C-F., Chen, C-S., Wang, P-W., Chang, Y-H., Ko, C-H. (2012). Social Anxiety in Online and Real-Life Interaction and Their Associated Factors. Cyberpsychol BehavSoc Netw, 15(1), 7-12. 